\title{
ОСОБЕННОСТИ ИЗУЧЕНИЯ ЛЕКСИЧЕСКОГО МАТЕРИАЛА НА УРОКАХ РУССКОГО ЯЗЫКА КАК ИНОСТРАННОГО
}

\section{FEATURES OF STUDYING LEXICAL MATERIAL IN RUSSIAN AS A FOREIGN LANGUAGE LESSONS}

\section{N. Serebrennikova}

Summary: This article discusses the ways of semanticizing lexical material in the lessons of Russian as a foreign language. We consider such methods of explaining the meaning of new words as translation, visibility, the use of antonyms and synonyms, the use of word-formation connections and semanticizing context.

Keywords: vocabulary, semantics, new words, visibility, semantics.

\author{
Серебренникова Надежда Геннадиевна \\ К.филол.н., доцент, Тамбовский государственный \\ университет им. Г.Р. Державина, \\ nadegda_korrespondensija@mail.ru
}

Аннотация: В данной статье говорится о способах семантизации лексического материала на уроках русского языка как иностранного. Рассматриваются такие способы объяснения значения новых слов, как перевод, наглядность, использование антонимов и синонимов, использование словообразовательных связей и семантизирующего контекста.

Ключевые слова: лексика, семантика, новые слова, наглядность, семантизация.

среди представленных в словаре, и не всегда, даже под руководством преподавателя, работая со словарем, студент в состоянии выбрать нужное в данном случае значение. Таким образом при выборе того или иного варианта нам нужно будет обращаться к минимальному контексту, в который может быть включено новое слово. С другой стороны, если мы изучаем слова, которые не являются многозначными или те, у которых наличие даже нескольких значений не вызывает больших затруднений, то выбор данного способа дает второе существенное преимущество - экономию времени. Однако и в этом случае данный способ нельзя назвать однозначно самым простым, самым удобным. Например, на начальном этапе это может даже затруднять процесс обучения, поскольку не способствует активному вовлечению в процесс урока: работа со словарем требует от студентов определённых навыков, а если слова переводятся учителем, то роль студента состоит лишь в том, чтобы записать перевод слова. К тому же лексика, изучаемая на начальном этапе, как правило, обозначает конкретные предметы, поэтому перевод таких слов, как "окно", "словарь", "ручка", "тетрадь", а также - "парк", "река", "улица", "площадь" по сути не будет экономить время, поскольку данные слова усвоятся значительно лучше при использовании наглядности.

Тем не менее прибегать к переводу на начальном этапе необходимо, в первую очередь, при изучении глаголов. Действие, безусловно, тоже может быть изображено наглядно, но без перевода нельзя точно объяснить значение, например, таких глаголов, как "изучать", "понимать", повторять" и многих других. В данном случае как раз наиболее целесообразным способом семантизации нового слова является перевод. 
Наиболее эффективным способом семантизации является наглядность. Так, например, А.В. Буланова отмечает, что чем разнообразнее восприятие учебного материала, тем более прочно он усваивается. Принцип наглядности, по мнению А.В. Булановой, связан с сущностью процесса восприятия, осмысления и обобщения обучаемыми изучаемого материала [2, с. 105]. "Наглядность - специально организованный показ языкового и экстралингвистического материала с целью облегчения его объяснения, усвоения и использования в речевой деятельности. Многие преподаватели русского языка используют прием наглядной семантизации, когда значение слова поясняется не путем перевода, а путем обозначаемого этим словом предмета или картинки..." [2, с. 105]. Правильно подобранные средства наглядности побуждают учащихся высказывать свое мнение и тем самым формируют навыки и умения выражать свои мысли. Наглядность, по мнению А.В. Булановой, имеет психологическое воздействие на слушателей в процессе обучения и помогает решить следующие учебные задачи:

- активизировать внимание и запоминание материала;

- повышать качество речемыслительного процесca;

- стимулировать интерес к предъявляемой и закрепляемой учебной информации;

- обеспечивать разнообразие способов деятельности слушателей [2, с. 105].

Важным в данном случае является то, что использование наглядности повышает внимание слушателей и активизирует речемыслительную деятельность, повышает мотивацию [3, с. 42]. Особенно эффективна зрительная наглядность. Работа с данным материалом должна побуждать учащихся к созданию собственного высказывания.

Следует отметить, что на начальном этапе обучения наглядность используется на каждом уроке. М.П. Чеснокова отмечает: "Наиболее эффективно с помощью различных видов наглядности семантизируются слова, обозначающие конкретные предметы, пространственные понятия, геометрические формы" [5, с.69]. Безусловно, наглядность делает учебный процесс интересным, способствует быстрому запоминанию слов, облегчает процесс повторения. В условиях использования различных технических средств обучения, возможности, которые открывает перед собой выбор данного способа семантизации, чрезвычайно велики. Разнообразны и виды наглядности. Это может быть подача нового материала в форме презентации, использование учебного фильма, фотографий, картинок, схем, а также демонстрация самих предметов. Так, при изучении лексической темы "Город" семантизация новой лексики, например, таких слов, как "автобус", "машина", "трамвай", парк", "рынок", "школа", "остановка автобуса" может осуществляться с помощью соответствующей презентации, где использу- ется изображение данных объектов, а также с помощью учебного фильма, где в игровой форме, во время воображаемой прогулки по городу, учащиеся запоминают различные названия. Тот же принцип наглядности может быть использован при изучении таких тем, как"В магазине”, "В столовой", "В ресторане”, где учащимся требуется усвоить много лексики, имеющей предметное значение. Например, при изучении темы “В магазине” без наглядности практически невозможно обойтись, поскольку иностранным студентам бывает очень трудно понять разницу в значении таких слов, как "коробка", "пачка", "пакет" и, соответственно, сочетаний "коробка конфет", "пачка масла", "пакет сока" и т. п. Пока учащимся не будут продемонстрированы данные упаковки, им бывает очень трудно уяснить разницу в значении этих слов, поскольку в их родном языке такая разница часто отсутствует. Использование наглядности в данном случае вызывает интерес и побуждает к сравнению значений данных слов в русском языке и языке учащихся, при этом студенты сами прибегают к переводу непроизвольно.

Также незаменима наглядность при семантизации глаголов движения с приставками, например, "обойти", "перейти", "пойти", "прийти"т. д. В родном языке учащихся значение данных глаголов передаётся грамматически совершенно иначе, и это, как правило, вызывает трудности. Но объяснить семантику данных слов не сложно, если прибегнуть при объяснении к помощи учебных фильмов, где продемонстрирован характер и направление движения. Закрепление материала в данном случае также может быть проведено с помощью учебного фильма, в котором человек проделывает определённый путь, а задача студентов - описать траекторию движения человека после просмотра фильма. Упрощенно то же упражнение может быть проделано на основе схемы, когда студенты, имея схему перед глазами, слушают текст, который читает преподаватель, например, на тему "Как я ходил в гости к другу", а затем, прослушав текст, должны восстановить его по памяти.

Разумеется, что применение наглядности не может ограничиваться темами, приведенными выше. Наглядность на занятиях должна использоваться постоянно, и преподаватель сам может выбирать, в каком объёме данный вид семантизации целесообразен при изучении определённой темы.

Использование антонимов является чрезвычайно эффективным способом объяснения новых слов на начальном этапе, т.к. в отличие, например, от использования синонимов, этот способ намного проще и не требует от учащихся определённой языковой подготовки и достаточно большого запаса слов. В первую очередь, данный способ используется при семантизации наречий и прилагательных. Имеются в виду такие наречия, как "хорошо - плохо", "тихо - громко", "быстро - медленно", "вверху - внизу", "впереди - сзади" и т. п. Изучение при- 
лагательных также невозможно без объяснения значений слов с помощью антонимов. Студенты чрезвычайно легко запоминают такие прилагательные, как "высокий - низкий", "широкий - узкий", "простой - сложный". К помощи антонимов преподаватель также часто прибегает при изучении глаголов движения с антонимичными приставками.

Весьма часто используется и такой способ, как подбор синонимов для объяснения значения нового слова. Но данный способ семантизации требует от учащихся определённого запаса слов, т. к. при объяснении значений синонимов необходимо прибегать к более пространному контексту, поскольку значения синонимов не тождественны. Иногда требуется объяснить учащимся стилистическую разницу в значении подобных слов. Так, например, иностранные студенты очень часто используют вариант "кушать" вместо варианта "есть", который является стилистически нейтральным. Безусловно, можно объяснить новый глагол "кушать" как синоним слова "есть", но следует уточнить, что глагол "кушать" редко используется в сочетании с местоимением"я" и употребляется обычно как вежливое приглашение к столу.

Весьма эффективным является метод объяснения новых слов путём указания на их словообразовательные связи [4, с. 231]. Так, например, слово "студенческий" объясняется с помощью слова "студент". Достаточно легко понимается учащимися значение таких однокоренных слов, как "читать", "чтение", "читатель" и т. п. Данный способ семантизации является универсальным и зависит, в первую очередь, не от выбранной лексической темы, а от того, к какой части речи относится изучаемое слово. Задача преподавателя заключается в том, чтобы студент уяснил грамматическое различие между такими частями речи, как существительное, прилагательное, глагол. В русском языке используется большое количество суффиксов и префиксов, и выбор их для иностранного студента часто вызывает большие затруднения. Но смысл использования данного способа семантизации заключается в том, чтобы студенты, видя ряд одноко- ренных слов, могли понять, какие из них обозначают производителя действия, какие - признак, а какие - сами действия. Например, зная значение слова"читатель", студент может легко догадаться о значении таких слов, как "посетитель" или "зритель".

Наиболее сложным в плане готовности учащихся к восприятию объяснения слова, является такой способ, как толкование значения слова с помощью семантизирующего контекста. В данном случае учащимся даётся предложение, в котором есть незнакомое для них слово, а студенты должны объяснить его значение исходя из словесного окружения. Таким образом формируется способность раскрыть значение незнакомой лексики через контекст. Подобное умение строится на использовании знаний в области словообразования, способности понять уже известные многозначные слова в новых значениях. Учащиеся должны понимать характер семантических связей в предложении, т.к. значение слова они могут понять благодаря пониманию общего смысла предложения. Например, анализируя фразу "Юрий Гагарин облетел вокруг нашей планеты", учащиеся могут понять значение нового слова "облетел". Также семантику нового слова учащиеся могут уяснить из ситуации, которая даётся в описательной или наглядной форме. И в данном случае такой способ семантизации тесно связан с наглядностью. На начальном этапе данный способ используется намного чаще, чем непосредственное обращение к речевому контексту.

Используя различные средства семантизации, преподаватель создает у учащихся определённую мотивацию. Студенты в процессе усвоения материала учатся выражать своё мнение, используя изучаемую лексику. Таким образом отрабатываются навыки устного общения и осваиваются определённые речевые ситуации, что делает обучение интересным и увлекательным. При этом выбор способа, с помощью которого осуществляется семантизация, во многом зависит от характера изучаемого материала. Преподаватель выбирает комбинацию способов или наиболее целесообразный на данном этапе обучения.

\section{ЛИТЕРАТУРА}

1. Альджалут, К.В. Из опыта обучения иностранных студентов лексике русского языка / К.В. Альджалут // Научно-методический электронный журнал "Концепт". - 2015. - Т. 24. - с. 155-157 - URL: http://e-koncept.ru/2015/95267.htm.

2. Буланова, А.В. Применение наглядности как средства создания коммуникативной мотивации при обучении русскому языку как иностранному / А.В. Буланова // Вестник Казанского юридического института МВД России. - 2014. - N 2(16). - С. 104-107.

3. Васильева, М.М. Условия формирования мотивации при изучении иностранного языка / М.М. Васильева // Иностранные языки в школе. - 2001. - N 2. C. 40-44.

4. Ковалева, А.В. Этапы работы с лексикой при обучении РКИ / А.В. Ковалева // Вестник ВГУ. Серия: Лингвистики и межкультурная коммуникация. - 2013. N 2. - C. 231-233.

5. Чеснокова, М.П. Методика преподавания русского языка как иностранного: учеб. пособие. - М.: МАДИ, 2015. - 132 с. 